\title{
Revisão das espécies sul-americanas de Rhopalophora (Coleoptera: Cerambycidae)
}

\author{
Dilma Solange Napp \\ ${ }^{1}$ Departamento de Zoologia, Universidade Federal do Paraná. Caixa Postal 19020, 81531-980 Curitiba, Paraná, Brasil. \\ E-mail: napp@ufpr.br. Pesquisador do CNPq.
}

\begin{abstract}
Revision of the South American species of Rhopalophora (Coleoptera: Cerambycidae). Rhopalophora AudinetServille, 1834 is currently composed of 25 species with a distribution ranging from North to South America. Only nine of them were described from South America and have been recorded exclusively from this continent. The North and Central American species were revised by GIESBERT \& CHEMSAK (1993); the South American species, on the other hand, still remain with their descriptions fragmented in different publications that date from 1824 to 1989.The purposes of this work are to redescribe the genus, to gather information on the South American species, to provide updated and standardized descriptions, illustrations, and an identification key, in order to complement that of Giesbert \& ChemsAK (1993). The following species are treated: $R$. collaris (Germar, 1824) (type species), R. pulverulenta Guérin-Méneville, 1844, R. venezuelensis Chevrolat, 1859, R. occipitalis Chevrolat, 1859, R. neivai Mendes, 1940, R. prolixa Monné, 1989, R. dyseidia Martins \& Napp, 1989, R. casignata Martins \& Napp, 1989, and R. paraensis Martins \& Napp, 1989.
\end{abstract}

KEY WORDS. Cerambycinae; Rhopalophorini; South America; taxonomy.

Rhopalophora foi proposto por AUdinET-SERVILLE (1834) para única espécie, $R$. sanguinicollis Audinet-Serville, 1834 ( = Callichroma collare Germar, 1824), descrita do Brasil. Atualmente, o gênero inclui 25 espécies com distribuição exclusiva nas Américas. Desse total, somente nove foram descritas da América do Sul e, até o momento, têm sido registradas apenas para esse continente (Monné 2005, Monné \& Hovore 2006). As espécies norte e centro-americanas foram revisadas por Giesbert \& Chemsak (1993), ao contrário das sul-americanas cujas descrições ainda permanecem dispersas em diferentes publicações (Germar 1824, Guérin-Méneville 1844, Chevrolat 1859, Mendes 1940, Martins \& Napp 1989, Monné 1989). Os principais objetivos desta contribuição são os de reunir as informações sobre as espécies sul-americanas; fornecer descrições atualizadas e padronizadas, ilustrações e chave para identificação das espécies; redescrever brevemente o gênero e, dessa forma, complementar a revisão de Giesbert \& CHemsak (1993).

Os imaturos das espécies sul-americanas são desconhecidos e apenas $R$. collaris (Germar, 1824) tem registro de hospedeiro: Citrus sp. (Rutaceae) (Monné 2001).

Siglas mencionadas no texto referem-se às seguintes instituições: (ACMS) American Coleoptera Museum, Coleção J. Wappes, San Antonio; (BMNH) The Natural History Museum, Londres; (DZUP) Departamento de Zoologia, Universidade Federal do Paraná, Curitiba; MNHN, Muséum National d'Histoire Naturelle, Paris; (MNRJ) Museu Nacional, Universidade Federal do Rio de Janeiro, Rio de Janeiro; (MPEG) Museu Paraense Emílio Goeldi, Belém; (MZSP) Museu de Zoologia, Universidade de São Paulo, São Paulo; (UFPB) Universidade Federal da Paraíba, João Pessoa.

Considerando a recente publicação do catálogo de Monné (2005), as referências sob cada táxon referem-se à descrição original e ao catálogo, acrescidas de outras quando pertinentes. A ordem das espécies no texto segue a sequência da chave. As medidas são fornecidas em milímetros.

\section{TAXONOMIA}

\section{Rhopalophora Audinet-Serville, 1834}

Rhopalophora Audinet-Serville, 1834: 100; Monné, 2005: 531 (catálogo); Monné \& Hovore, 2006: 129 (checklist). Rhopalophorus; LeConte, 1873: 307 (error).

Espécie-tipo: Rhopalophora sanguinicollis Audinet-Serville, 1834, por monotipia ( = Callichroma collare Germar, 1824).

Tinopus LeConte, 1850: 19.

Espécie-tipo: Stenocorus longipes Say, 1824, por monotipia.

Fronte transversa, declive, um pouco deprimida com o limite com as genas um pouco elevado e angulosa entre os tubérculos anteníferos que são ligeiramente acuminados ou arredondados no topo. Genas com cerca de metade da maior largura dos lobos oculares inferiores (exceto R. collaris e $R$. dyseidia). Olhos muito finamente granulados, chanfrados; lobos oculares inferiores bem desenvolvidos, proeminentes, ocupam toda a região lateral da cabeça; ligados aos superiores por faixa de seis a sete omatídios, pouco mais estreita que os lobos superiores; lobos superiores estreitos, com cerca de um quarto da largura dos lobos inferiores e tão distantes entre si quanto o quádruplo de um lobo. Mandíbulas delgadas, sem dimorfismo, arredondadas no terço apical e aguçadas no ápice; margem interna com franja de pêlos. Maxilas: gálea mais longa que o palpo maxilar, cilíndrica e expandida no ápice que é obliquamente truncado; artículo apical dos palpos maxilares encurtado, tão longo quanto o basal e atenuado no ápice; segundo e terceiro artículos cônicos e subiguais 
(Marques \& NapP 2003: 518, fig. 61). Antenas com onze artículos, filiformes, inermes e sem carenas; nos machos ultrapassam o ápice elitral em quatro a cinco artículos, nas fêmeas em dois a três artículos. Flagelômeros cilíndricos, subglabros, os distais mais alongados e com pubescência esbranquiçada mais aparente. Com poucas exceções, antenômero IV com metade do comprimento dos antenômeros III e V e, pelo menos, os antenômeros VI-VIII mais longos que o III; XI não apendiculado, rombo no ápice e, nos machos, via de regra, mais longo que o III. Protórax mais longo que largo, subcilíndrico, mais atenuado para a margem anterior; lados usualmente subtuberculados. Pronoto com ou sem gibosidades. Processo prosternal curvo, com lados paralelos entre as procoxas e expandido para o ápice que alcança a margem anterior do mesosterno; entre as procoxas com cerca de um terço da largura da coxa. Cavidades procoxais arredondadas nos lados e quase fechadas atrás pela projeção apical do processo prosternal e pelo proepimero que se projeta até além da metade do diâmetro da cavidade cotilóide. Processo mesosternal aplanado, retangular, cerca de vez e meia a largura da mesocoxa; apenas emarginado no ápice que é firmemente acoplado à projeção anterior do metasterno tão larga quanto o processo mesosternal. Cavidades mesocoxais fechadas nos lados. Mesosterno, metasterno e urosternitos revestidos por densa pilosidade serícea ou com brilho oliváceo que oblitera o tegumento. Urosternito I conspicuamente mais longo que o II, com projeção intercoxal um pouco alargada e subarredondada no ápice; urosternito $\mathrm{V}$, nos dois sexos, um pouco alongado, pouco e gradualmente atenuado para o ápice que é arredondado. Escutelo pequeno, quadrangular, fortemente opaco e revestido por pubescência que oblitera o tegumento. Élitros alongados e estreitos, paralelos nos lados e atenuados nos ápices. Com pontos grossos, não alinhados, profundos e mais evidentes na metade basal, depois progressivamente mais finos e rasos para os ápices (exceto $R$. $d y$ seidia e $R$. casignata). Epipleuras quase verticais na metade basal e com pontuação semelhante à dos élitros; margem usualmente sem pontos ásperos e sem aspecto serreado. Pro- e mesocoxas arredondadas. Fêmures com pedúnculo longo e clava abrupta no terço apical (exceto R. dyseidia); pedúnculos carenados e sulcados (exceto R. dyseidia e R. casignata), sem asperosidades; metafêmures, nos machos, ultrapassam o ápice elitral, pelo menos, pela metade do comprimento da clava (exceto $R$. dyseidia). Metatíbias delgadas e comprimidas (exceto R. dyseidia), sem carenas e sem asperosidades; subglabras, com cerdas esparsas. Esporões tibiais moderadamente longos, mais evidentemente o interno. Metatarsômero I delgado, pelo menos um terço mais longo que II+III; meso- e metatarsômeros I-II com faixa glabra central.

Comentários. Rhopalophora é semelhantes a Aguassay Napp \& Mermudes, 2001 pelo antenômero IV com cerca da metade do comprimento do V, escapo alongado com sulco dorsal, protórax cilíndrico e gradualmente atenuado da base para o ápice, processo mesosternal largo e fêmures longamente pedunculados e clavados. Aguassay, originalmente descrito na tribo Cleomenini (Napp \& Mermudes 2001), foi transferido para
Rhopalophorini por MERMUDEs \& NAPP (2004). Rhopalophora distingue-se de Aguassay pela cabeça pouco projetada à frente dos olhos com a fronte transversa e genas, no máximo, com dois terços da largura do lobo ocular inferior; pelo escapo, no máximo, pouco mais longo que metade do comprimento do III; pelos élitros e epipleuras sem costas, os élitros paralelos nos lados; pelo processo mesosternal aplanado e cerca de vez e meia mais largo que a mesocoxa e pelas clavas robustas e fortemente abruptas. Em Aguassay, a cabeça é rostrada, com a fronte pouco mais longa que larga e as genas tão longas quanto a largura do lobo ocular inferior; o escapo é quase tão longo quanto o antenômero III; os élitros têm costa proeminente sobre as epipleuras que são verticais, deprimidas em todo o comprimento e carenadas na margem; os élitros são sinuosos nos lados, um pouco adelgaçados à frente do meio; o processo mesosternal é moderadamente elevado e apenas mais largo que a mesocoxa e as clavas são delgadas e não fortemente abruptas (NAPP \& Mermudes 2001: 4, fig. 3; Mermudes \& Napp 2004: 269, fig. 124).

\section{Chave para as espécies sul-americanas de Rhopalophora}

1. Protórax e élitros amarelados ou alaranjados, colorido não contrastante ..................................................................... 2

1'. Protórax com colorido diferente do colorido dos élitros...3

2. Protórax distintamente estreitado à frente do meio, com gibosidades laterais na metade posterior; lados com faixa longitudinal glabra e sem pontos. Escapo delgado, com sulco longitudinal da base até quase o ápice e pontuação fina (Fig. 1). Colômbia ..... R. pulverulenta Guérin-Méneville, 1844

2 '. Protórax não atenuado à frente do meio, sem gibosidades laterais; lados sem faixa longitudinal glabra e com pontos. Escapo robusto com depressão rasa na base, densamente pontuado-rugoso (Fig. 2). Brasil (São Paulo ao Rio Grande do Sul) R. neivai Mendes, 1940

3. Fêmures bicolores com o pedúnculo alaranjado e clava preta; pedúnculos sem sulco ou carena. Élitros com pubescência esparsa

.. 4

3'. Fêmures unicolores, pretos; pedúnculos carenados e sulcados. Élitros com pilosidade densa .. 5

4. Macho. Metafêmures ultrapassam o ápice elitral por cerca de dois terços do comprimento da clava, abrupta e com um terço do comprimento do fêmur. Prosterno sem áreas opacas e glabras. Protórax (Fig. 17) cilíndrico-alongado. Élitros sem pubescência serícea densa nos lados do escutelo e da sutura. Corpo delgado (Fig. 3). Equador .....

R. casignata Martins \& Napp, 1989

4'. Macho. Metafêmures apenas atingem o ápice elitral, com clava quase tão longa quanto metade do comprimento do fêmur. Protórax (Fig. 18) quadrangular. Prosterno com duas grandes áreas opacas, glabras e com pontos esparsos. Élitros com pubescência serícea densa aos lados do escutelo e ao longo da sutura. Corpo robusto (Fig. 4). Equador

R. dyseidia Martins \& Napp, 1989 
5. Protórax preto. Pronoto e lados do protórax (Figs 11 e 12) com pilosidade dourada compacta, deixando três estreitas faixas glabras e impontuadas, uma centro-longitudinal no pronoto e uma a cada lado do protórax (Fig. 5). Venezuela R. venezuelensis Chevrolat, 1859

5'. Protórax vermelho-alaranjado 6

6. Escapo sem sulco dorsal, apenas deprimido na base e mais curto que metade do comprimento do antenômero III. Antenômero IV com dois terços do comprimento do III e do V; III com sulco raso. Pronoto (Fig. 13) e lados do protórax revestidos por densa pilosidade amarelo-dourada (Fig. 7). Brasil (Bahia, Minas Gerais) ...........R. prolixa Monné, 1989

6'. Escapo com sulco da base ao ápice e com dois terços do comprimento do antenômero III. Antenômero IV com metade do comprimento do III e do V; III sem sulco. Pronoto e lados do protórax com pubescência esparsa 7

7. Protórax (Fig. 16) evidentemente estreitado no terço anterior e expandido em largo tubérculo obtuso mediano. Pronoto irregular, com duas gibosidades látero-basais e duas láteromedianas bem aparentes (Fig. 6). Brasil (Pernambuco ao Rio Grande do Sul), Bolívia, Paraguai, Argentina, Uruguai R. collaris (Germar, 1824)

7'. Protórax subcilíndrico, pouco e gradualmente alargado da margem anterior para trás. Gibosidades do pronoto quase nulas ou ausentes

8. Protórax (Fig. 14) atenuado do meio para a margem anterior, com tubérculo mediano pouco manifesto e outro menos aparente no terço posterior. Pronoto com pubescência amarelo-dourada curta e esparsa; gibosidades látero-basais aparentes. Élitros com pubescência longa, sedosa com brilho amarelado, exceto nos lados quase glabros e com faixa de tegumento escurecida. Cabeça preta com o vértice vermelho-alaranjado; fronte e clípeo com pubescência amarelo-dourada densa (Fig. 8). Brasil (Ceará, Rio Grande do Norte, Paraíba, Sergipe, Bahia)

R. occipitalis Chevrolat, 1859

8'. Protórax (Fig. 15) subcilíndrico, pouco atenuado do terço posterior para a margem anterior, a maior largura após o meio. Pronoto glabro, as gibosidades látero-basais pouco aparentes. Élitros com pubescência serícea muito curta, sem faixa escura contrastante nos lados. Cabeça inteiramente preta com pubescência esparsa (Fig. 9). Brasil (Pará) ........ R. paraensis Martins \& Napp, 1989

\section{Rhopalophora pulverulenta Guérin-Méneville, 1844} Figs 1, 10

Rhopalophora pulverulenta Guérin-Méneville, 1844: 235; Monné, 2005: 535 (catálogo); Monné \& Hovore, 2006: 129 (checklist).

Macho. Cabeça, protórax, escutelo e élitros alaranjados, concolores. Antenas e pernas pretas. Mesosterno, metasterno e urosternitos castanhos. Fronte, clípeo e dorso da cabeça reves- tidos por pilosidade amarelo-dourada densa; mais esparsa nas genas e mais longa e muito densa em forma de franja compacta em toda a margem inferior dos lobos oculares inferiores. Submento quase glabro, com rugas e pontos irregulares. Antenas ultrapassam o ápice elitral em 4,0-5,0 artículos. Escapo cilíndrico, delgado, com sulco longitudinal da base até quase o ápice, com metade do comprimento do III e tão longo quanto o IV; com pontuação fina, rasa e densa em toda a superfície e pubescência branco-amarelada, sedosa e bem aparente. Antenômeros VI-IX mais longos que o III, especialmente os VI-VII; XI tão longo quanto o III. Protórax (Fig. 10) expandido em tubérculo largo e arredondado no meio dos lados; mais atenuado do meio para a margem anterior e pouco atenuado do meio para a margem posterior com tubérculo pouco manifesto no terço posterior. Pronoto algo irregular, com duas gibosidades látero-basais e duas látero-medianas menos manifestas; revestido por densa pubescência amarelo-dourada que oblitera totalmente o tegumento, exceto em faixa centro-longitudinal, estreita, da base ao ápice, opaca e impontuada. Lados do protórax com larga área em forma de faixa longitudinal, da base ao ápice, opaca, glabra e sem pontos, delimitada nos lados e nas margens anterior e posterior pela pilosidade que reveste o pronoto e o prosterno. Prosterno, exceto no terço anterior, revestido por densa pilosidade branco-amarelada, sedosa que oblitera o tegumento, especialmente no disco e no processo prosternal; a cada lado com área quadrangular opaca, glabra e com pontos grossos e irregulares. Mesosterno, metasterno e urosternitos revestidos por densa pubescência sedosa com brilho oliváceo. Escutelo revestido por pilosidade amarelo-dourada. Élitros deprimidos no dorso, mais evidentemente na base. Com pilosidade amarelada, densa, oblitera parcialmente a pontuação até o terço apical onde os pontos são totalmente obliterados pela pilosidade. Extremidades elitrais transversalmente truncadas, com espinho sutural curto e delgado, o ângulo externo dentiforme. Fêmures com pubescência brancoamarelada bem aparente, especialmente no pedúnculo, com raros pontos ásperos. Metafêmures ultrapassam o ápice elitral por todo o comprimento da clava.

Fêmea. Não examinada.

Dimensões, macho. Comprimento total, 10,8-13,7; comprimento do protórax, 2,5-3,2; maior largura do protórax, 2,02,6; largura na margem anterior do protórax, 1,5-2,0; comprimento do élitro, 7,3-9,2; largura umeral, 2,5-3,3.

Material-tipo. Holótipo macho, descrito da Colômbia (MNHN, Coleção Thomson), examinado, porta as seguintes etiquetas: 1) Rhopalophora pulverulenta Guer.; ic. R. a. (type); Santa Fé; 2) Type; Guerin Men.; 3) Type.

Comentários. Rhopalophora pulverulenta e $R$. neivai são as únicas espécies sul-americanas que apresentam o tegumento da cabeça, protórax, escutelo e élitros alaranjados. As duas espécies distinguem-se prontamente pelos caracteres fornecidos na chave e pela distribuição geográfica totalmente distinta. Vide outros comentários sobre $R$. pulverulenta em $R$. venezuelensis. 
Material adicional examinado. Macho (MNHN, Coleção Bates), sem detalhes de procedência, comparado ao holótipo. Colômbia: Florencia, macho, 30.III.1972, Jiménez leg. (MZSP). Não foi possível determinar qual o Departamento, já que "Florencia" aparece como cidade em cerca de 15 Departamentos da Colômbia.

\section{Rhopalophora neivai Mendes, 1940}

Fig. 2

Rhopalophora (Rhopalophora) neivai Mendes, 1940: 380. Rhopalophora neivai; Monné, 2005: 534 (catálogo); Monné \& Hovore, 2006: 129 (checklist).

Macho. Cabeça, protórax, escutelo e élitros amareloalaranjados; a cabeça, às vezes, mais escura ou os élitros mais amarelados. Antenas e pernas pretas, as clavas dos fêmures até castanho-avermelhadas. Mesosterno, metasterno e urosternitos castanho-escuros. Cabeça com pontuação fina, rasa e densa. Fronte, clípeo e dorso da cabeça revestidos por pilosidade amarelo-dourada densa que oblitera, ou quase, o tegumento. Pilosidade amarelo-esbranquiçada nas genas e em forma de faixa que contorna a margem inferior dos lobos oculares inferiores. Submento subglabro, com pontos grossos, irregulares e esparsos. Face ventral da cabeça brilhante, sem rugas transversais. Antenas ultrapassam o ápice elitral em 3,0-4,0 artículos. Escapo algo robusto, quase tão largo na base quanto no ápice, pouco mais curto que o III e o IV; sem sulco longitudinal, apenas deprimido na base; opaco, com pontuação densa e corrugada em toda a superfície e pubescência esparsa. Antenômeros III e V com comprimentos subiguais; VI-IX mais longos que o III; XI apenas mais longo que o III. Protórax pouco alongado, subcilíndrico, apenas atenuado para a margem anterior e ligeiramente expandido logo após o meio. Pronoto um pouco irregular, com duas gibosidades látero-basais e apenas deprimido no terço anterior; revestido por pilosidade amarelo-dourada que quase oblitera o tegumento. Lados do protórax com pontuação mais aparente e pilosidade mais esparsa do que no pronoto. Prosterno opaco, com pontos moderadamente grossos e regularmente distribuídos em toda a superfície; subglabro, exceto em faixa centro-longitudinal e no processo prosternal com densa pilosidade amarelada. Mesosterno, metasterno e urosternitos revestidos por pubescência serícea. Escutelo revestido por pilosidade amarelo-dourada densa. Élitros opacos, praticamente não deprimidos na base; com pubescência amarelo-sedosa densa que não oblitera os pontos. Extremidades elitrais obliquamente truncadas e inermes. Fêmures com pubescência esbranquiçada aparente, mais esparsa nas clavas, com cerdas esbranquiçadas, curtas e esparsas. Metafêmures ultrapassam o ápice elitral por cerca de dois terços do comprimento da clava.

Fêmea. Antenas ultrapassam o ápice elitral em dois artículos; VI-IX com comprimentos subiguais ao III; XI tão longo quanto o III. Protórax mais expandido nos lados após o meio; pronoto com duas gibosidades látero-medianas além das láterobasais. Prosterno com pontos grossos e irregulares. Élitros com carena dorso-lateral pouco aparente da base até próximo ao ápice. Clavas dos fêmures mais delgadas, o ápice das posteriores atinge o ápice elitral.

Dimensões, macho/fêmea, respectivamente. Comprimento total, 8,5-8,9/8,7-9,2; comprimento do protórax, 1,6-1,7/1,61,7 ; maior largura do protórax, 1,3-1,5/1,4-1,5; largura do protórax na margem anterior, 1,2-1,3/1,2-1,3; comprimento do élitro, 6,2-6,6/6,3-6,8; largura umeral, 1,7-1,8/1,7-1,8.

Material-tipo. Holótipo fêmea, BRASIL, Santa Catarina: Nova Teutônia (atualmente Seara), 8.X.1936, F. Plaumann leg. (MZSP), examinado. No MZSP existem outros dois exemplares (macho do Paraná: Rio Negro, 25.X.1928, fêmea de Santa Catarina: Mafra, XII.1933, A. Maller leg.), identificados pelo autor da espécie e que portam rótulos de "paratypo". Trata-se de um equívoco já que Mendes (1940: 380) diz, claramente: “A espécie é representada por um só exemplar..." e no materialtipo (p. 381) menciona apenas o holótipo.

Material examinado. Brasil, Paraná: Curitiba, fêmea, 17.VIII.1987, G. H. Rosado-Neto leg. Guarapuava, macho, 1942, F. Justus leg. Ponta Grossa, fêmea, X.1948, F. Justus leg. Santa Catarina: Mafra, macho, I.1971, A. Maller leg.; Seara (Nova Teutônia), macho, fêmea, VIII.1941, macho, 31.VIII.1961, fêmea, 5.IX.1961, F. Plaumann leg. Todos no DZUP.

\section{Rhopalophora casignata Martins \& Napp, 1989}

\section{Figs 3, 17}

Rhopalophora (Rhopalophora) casignata Martins \& Napp, 1989: 62, fig. 3.

Rhopalophora casignata; Monné, 2005: 532 (catálogo); Monné \& Hovore, 2006: 129 (checklist).

Macho. Cabeça, protórax, escutelo e face ventral do corpo, pretos. Antenas com o escapo preto e flagelômeros castanhos. Élitros castanho-claros. Pernas bicolores: pretas com o pedúnculo dos fêmures alaranjado. Cabeça com pontos grossos e densos quase totalmente obliterados pela pilosidade dourada que reveste a fronte, o clípeo e o dorso da cabeça; genas com pontos finos, rasos e pubescência amarelo-esbranquiçada. Margem inferior dos lobos oculares inferiores com pubescência amarelo-esbranquiçada densa. Face ventral da cabeça com algumas rugas grossas e pontos esparsos; região anterior do submento com pontos muito grossos e profundos; pêlos esbranquiçados, longos e esparsos em toda a superfície. Antenas ultrapassam o ápice elitral em 4,0 artículos. Escapo cilíndrico, quase tão largo na base quanto no ápice, abaulado no dorso, sem sulco ou depressão na base, com dois terços do comprimento do III; subglabro, com pontuação fina e corrugada em toda a superfície. Antenômeros III-V(VI) brilhantes, subglabros; pubescência esbranquiçada aparente nos VIII-XI. Antenômero IV com dois terços do comprimento do III e do V; V-VII tão longos quanto o III; VIII-X subiguais e decrescentes; XI pouco mais curto que o III. Protórax (Fig. 17) cilíndrico, pouco atenuado para a margem anterior, sem tubérculos laterais, com a largura na margem anterior subigual à mediana. Pronoto subconvexo, sem gibosi- 

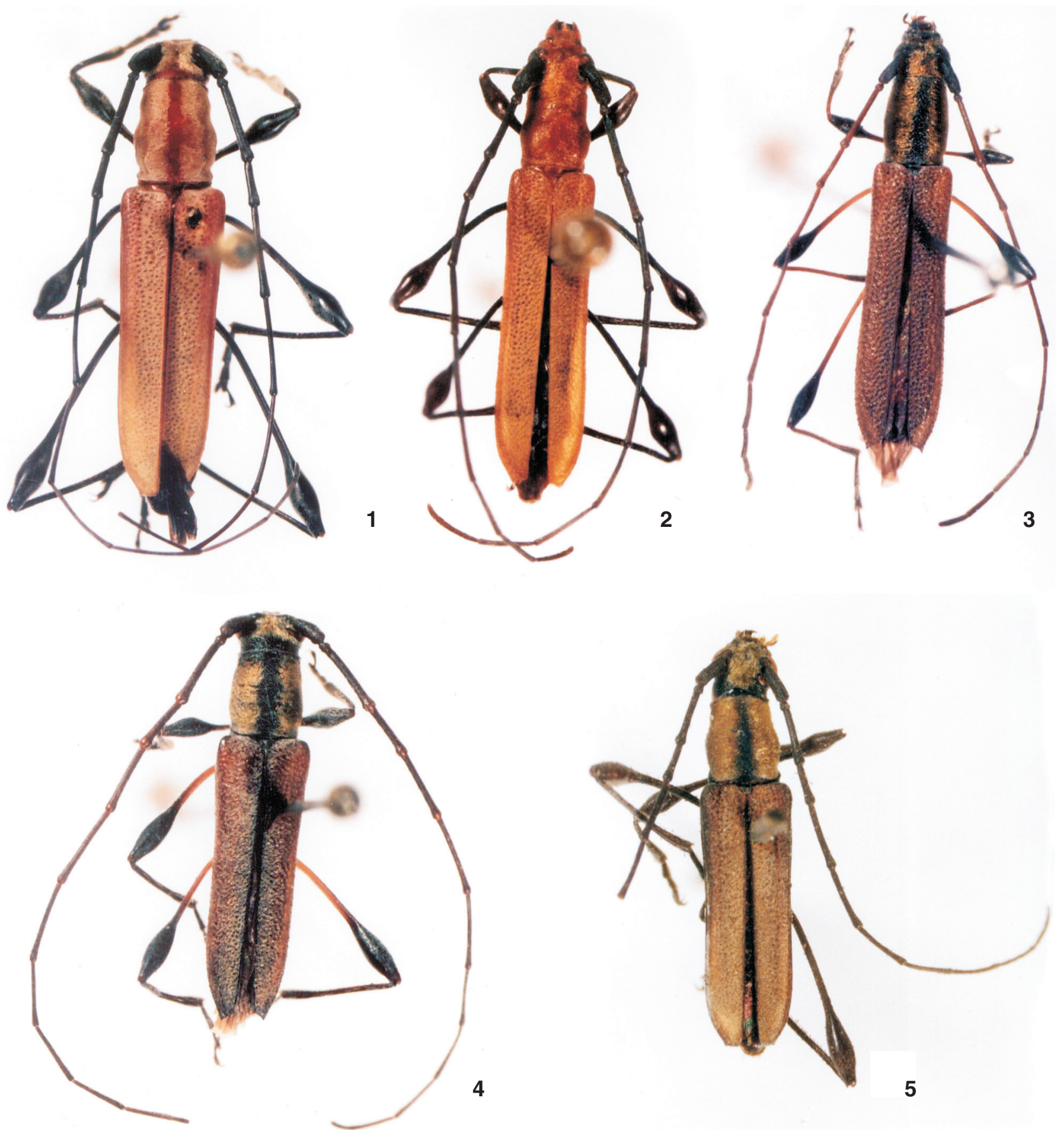

Figuras 1-5. Habitus: (1) Rhopalophora pulverulenta, macho, 13,7 mm; (2) R. neivai, macho, 8,5 mm; (3) R. casignata, holótipo macho, 7,3 mm; (4) R. dyseidia, holótipo macho, 8,6 mm; (5) R. venezuelensis, sintipo fêmea, 10,2 mm.

dades; revestido por pilosidade amarelo-dourada, compacta que oblitera o tegumento, exceto em faixa centro-longitudinal glabra, com pontos grossos, profundos e subcontíguos. Lados do protórax com pilosidade igual à do pronoto; no limite com o prosterno e na base com pilosidade esbranquiçada. Prosterno opaco com pontos grossos, profundos e irregularmente esparsos; pubescência serícea reveste quase toda a superfície, especialmente o centro do disco e o processo prosternal; a cada lado com 
área quadrangular quase glabra e aparente apenas de acordo com a incidência da luz. Mesosterno, metasterno e urosternitos revestidos por pubescência serícea compacta, mas que permite entrever a pontuação grossa e densa do metasterno e urosternitos. Escutelo revestido por pubescência serícea densa. Élitros não deprimidos no dorso, com pontos grossos, profundos e contíguos em toda a superfície. Pilosidade serícea curta e pouco aparente e cerdas esbranquiçadas, eretas e esparsas em toda a superfície. Epipleuras declives com pontos grossos, profundos, subcontíguos e mais ou menos alinhados em duas fileiras; margem com pontos ásperos esparsos, providos de cerdas curtas, esbranquiçadas. Extremidades elitrais obliquamente truncadas com espinho robusto no ângulo externo e curto, delgado no ângulo sutural. Fêmures delgados, cilíndricos, sem sulco ou carena; quase lisos, com pubescência esbranquiçada muito esparsa e algumas cerdas curtas e esbranquiçadas; clavas esparsamente pubescentes e com algumas cerdas curtas e esbranquiçadas. Metafêmures com clava abrupta no terço apical, ultrapassam o ápice elitral por dois terços do comprimento da clava. Metatíbias cilíndricas.

Fêmea. Antenas ultrapassam o ápice elitral em cerca de três artículos; XI um terço mais curto que o III. Prosterno fortemente opaco, muito irregularmente corrugado com pontos pouco aparentes e sem áreas diferenciadas. Metafêmures ultrapassam o ápice elitral em cerca da metade do comprimento da clava.

Dimensões, macho/fêmea, respectivamente. Comprimento total, 6,6-7,3/6,7-6,8; comprimento do protórax, 1,5-1,6/1,5; maior largura do protórax, 1,0-1,2/1,1-1,2; largura da margem anterior do protórax, 0,8/1,0; comprimento do élitro, 4,7-5,3/ 4,7-4,8; largura umeral, 1,3-1,5/1,3.

Material-tipo. Holótipo macho, EQUADOR, Manabí: Jipijapa, 12.V.1965 (MZSP), examinado.

Comentários. Rhopalophora casignata e R. dyseidia são as duas únicas espécies sul-americanas com fêmures bicolores, sem sulco ou carena e élitros esparsamente pubescentes, com pontos grossos, profundos e contíguos em toda a superfície. Até o momento, são as únicas descritas do Equador e com registro apenas para este país. As duas espécies distinguem-se pelos caracteres fornecidos na chave.

Martins \& NAPp (1989: 62) não fazem menção às áreas diferenciadas no prosterno do macho e descrevem que as antenas ultrapassam o ápice elitral por três artículos e que os metafêmures sobrepassam o ápice elitral por um terço do comprimento da clava. No macho ora examinado, as antenas e os metafêmures são mais longos e o prosterno apresenta áreas diferenciadas embora pouco aparentes. Nas duas fêmeas examinadas, a pilosidade em geral está mal conservada o que dificulta sua comparação com a do macho.

Material examinado. EquAdor. Guayas: Guaiaquil (50 m), macho, 1-2.III.1981, 2 fêmeas (40 Km SW, 50 m), 21-22.III.1981, H. F. Howden leg. (MZSP). Manabí: Jipijapa, macho, 12.V.1965 (MZSP, holótipo).

\section{Rhopalophora dyseidia Martins \& Napp, 1989} Figs 4, 18

Rhopalophora (Rhopalophora) dyseidia Martins \& Napp, 1989: 60, fig. 4.

Rhopalophora dyseidia; Monné, 2005: 533 (catálogo); Monné \& Hovore, 2006: 129 (checklist).

Macho. Cabeça, protórax, escutelo e face ventral do corpo, pretos. Antenas pretas ou com os flagelômeros castanhoavermelhados. Élitros castanho-claros. Pernas bicolores: pretas com o pedúnculo dos fêmures alaranjado. Fronte, clípeo e dorso da cabeça revestidos por pilosidade sedosa densa, amarelodourada no vértice e mais esbranquiçada na fronte e no clípeo, oblitera o tegumento. Margem inferior dos lobos oculares inferiores e genas com pilosidade serícea densa. Face ventral da cabeça com rugas grossas; próximo à margem anterior com pontos grossos e densos; pêlos esbranquiçados longos e esparsos em toda a superfície. Antenas ultrapassam o ápice elitral em cerca de 4,0 artículos. Escapo um pouco robusto, quase tão largo na base quanto no ápice, sem sulco dorsal e ligeiramente deprimido na base; pouco mais longo que metade do comprimento do III; brilhante, densamente pontuado-rugoso em toda a superfície, com pêlos longos, esbranquiçados e esparsos; pubescência ausente. Antenômeros III-VI subglabros, com pontos finos, ligeiramente ásperos e muito esparsos; face inferior dos III-IV com pontos ásperos e cerdas esbranquiçadas, esparsos; VII-XI com pubescência esbranquiçada. Antenômero IV com cerca de dois terços do comprimento do III e do V; V tão longo quanto o III; VI-VII pouco mais longos que o III; VIII-X subiguais e decrescentes; XI tão longo quanto o III. Protórax (Fig. 18) quadrangular, proporcionalmente pouco alongado, tão largo na base quanto no ápice e sem tubérculos laterais. Pronoto regular e pouco convexo, as gibosidades látero-basais quase nulas, as látero-medianas ausentes; revestido por pilosidade amarelo-dourada ou esbranquiçada, compacta que oblitera totalmente o tegumento, exceto em faixa centro-longitudinal glabra e com pontos moderadamente grossos, profundos e subcontíguos; cerdas esbranquiçadas longas e esparsas em toda a superfície. Lados do protórax revestidos por densa pilosidade que oblitera o tegumento; dourada próximo do pronoto e esbranquiçada no restante. Prosterno com duas amplas áreas subarredondadas, opacas, glabras e com pontos esparsos, ocupam quase toda a superfície e separadas por estreita faixa de pilosidade serícea; processo prosternal e margem anterior das procoxas revestidos por densa pilosidade serícea que se continua nos lados do prosterno contornando as áreas glabras. Mesosterno, metasterno e urosternitos revestidos por pilosidade serícea um pouco alongada e compacta, mas que permite entrever a pontuação grossa e densa do metasterno e urosternitos. Escutelo revestido por pubescência serícea densa. Élitros não deprimidos no dorso, com pontos grossos, profundos, densos a corrugados em toda a superfície. Pilosidade serícea esparsa; mais aparente nos lados do escutelo e ao longo da sutura; cerdas 
esbranquiçadas longas, eretas e esparsas em toda a superfície. Epipleuras subverticais no terço basal; com pontuação grossa, densa a corrugada e pilosidade esparsa; margem com pontos ásperos diminutos cada um provido de cerda longa e esbranquiçada. Extremidades obliquamente truncadas com espinho robusto no ângulo externo e curto, delgado no ângulo sutural. Fêmures com pedúnculo cilíndrico, sem sulco ou carena, com cerdas esbranquiçadas longas e esparsas e pubescência pouco aparente; clavas com pubescência e cerdas longas, esbranquiçadas e esparsas. Metafêmures quase alcançam o ápice elitral; clavas alongadas com cerca da metade do comprimento total dos fêmures. Tíbias cilíndricas.

Fêmea. Desconhecida.

Dimensões, macho. Comprimento total, 7,3-8,6; comprimento do protórax, 1,5-1,8; maior largura do protórax, 1,31,5; largura da margem anterior do protórax, 1,2-1,3; comprimento do élitro, 5,1-5,8; largura umeral, 1,7-2,0.

Variabilidade. No exemplar de Catamayo, a pilosidade que reveste a cabeça, o pronoto e os lados do protórax é branco-amarelada.

Material-tipo. Holótipo e parátipo machos, descritos do Equador, Loja: Loja, 8.V.1965, Peña leg. (MZSP). Examinado o holótipo.

Material adicional examinado. EquADor. Loja: Catamayo (13,5 km W, 2050 m), macho, 19.III.1996, D. Bizoska leg. (MZSP).

\section{Rhopalophora venezuelensis Chevrolat, 1859}

Figs 5, 11, 12

Rhopalophora (Rhopalophora) venezuelensis Chevrolat, 1859: 60. Rhopalophora venezuelensis; Rojas, 1866: 243; Monné, 2005: 536 (catálogo); Monné \& Hovore, 2006: 130 (checklist).

Síntipo fêmea. Colorido geral negro-acastanhado. Cabeça, antenas, protórax, escutelo, mesosterno, metasterno e pernas, negros, as clavas posteriores mais acastanhadas. Élitros castanho-alaranjados com as epipleuras mais escuras. Urosternitos acastanhados. Fronte, clípeo e vértice revestidos por densa pilosidade amarelo-dourada, sedosa, oblitera totalmente o tegumento. Genas com pubescência esbranquiçada esparsa. Margem inferior dos olhos contornada por pubescência esbranquiçada curta. Antenas ultrapassam o ápice elitral em 4,0 artículos. Escapo cilíndrico, com sulco dorsal da base até quase o ápice, cerca de um terço mais curto que o antenômero III; muito fina e densamente pontuado com pubescência esbranquiçada bem aparente. Antenômeros III-XI muito fina e densamente pontuados e pubescentes, a pubescência mais aparente para os distais. Antenômero IV com metade do comprimento do V; V-IX com comprimentos iguais e pouco mais longos que o III; XI tão longo quanto o III. Protórax (Figs 11 e 12) mais atenuado para a margem anterior, com expansão arredondada mediana. Pronoto sem gibosidades, revestido por pilosidade dourada compacta, contrastante com o tegumento preto totalmente obliterado, exceto em faixa centro-longitudinal glabra, opaca e sem pontos; a pilosidade dourada se estende um pouco nos lados do protórax onde é delimitada por pubescência esbranquiçada. Lados do protórax com estreita faixa longitudinal preta, opaca, glabra, com pontos muito esparsos. Prosterno com grossas rugas transversais, revestido por pilosidade esbranquiçada, sedosa, mais aparente no centro do prosterno. Mesosterno, metasterno e urosternitos revestidos por pubescência serícea. Escutelo revestido por pubescência amareloesbranquiçada densa. Élitros pouco deprimidos no dorso com pontos grossos, profundos, quase totalmente obliterados pela densa pilosidade serícea e gradativamente mais finos, rasos e pouco aparentes para os ápices e ao longo da sutura; a pontuação, em geral, mais rasa do que o usual. Epipleuras subverticais na metade basal, com pontos grossos e profundos; na metade apical com pontos gradativamente menores e mais rasos, obliterados pela pubescência. Extremidades elitrais transversalmente truncadas com espinho curto no ângulo externo, o sutural inerme. Fêmures com pubescência esbranquiçada aparente, especialmente no pedúnculo. Metafêmures ultrapassam o ápice elitral por dois terços do comprimento da clava.

Macho. Não examinado. Chevrolat (1859: 61) descreve que as antenas têm vez e meia o comprimento do corpo, os fêmures são sulcados e as clavas são abruptas.

Dimensões, síntipo fêmea. Comprimento total, 10,2; comprimento do protórax, 2,2; maior largura do protórax, 1,8; comprimento do élitro, 6,8; largura umeral, 2,3.

Material-tipo. Pela descrição original, Chevrolat (1859: 60) teve em mãos, pelo menos, dois exemplares provenientes da Venezuela, Distrito Federal: Caracas, Rojas leg. Tavakilian (1999) menciona a existência de síntipo macho no MNHN (Coleção Thomson) e síntipos no BMNH (Coleções Chevrolat e Sallé). A descrição acima está baseada no exame de um síntipo fêmea, depositado no BMNH e que porta as etiquetas: 1) Type (redonda com a margem vermelha); 2) Rhopalophora venezuelensis Chevr.; Caracas; 3) Rh. Venezuelensis Chev., 1859 (branca, manuscrita); 4) Bowr. Chevr. 63.47. Este exemplar encontra-se mal conservado, com a antena esquerda quebrada e a perna posterior esquerda colada na etiqueta "Type"; a pilosidade em geral danificada dificultou sua correta descrição.

Comentários. Rhopalophora venezuelensis é muito semelhante a $R$. pulverulenta Guérin-Méneville, 1844 descrita da Colômbia e difere, basicamente, pelo colorido preto da cabeça, do protórax e do escutelo, pelas epipleuras castanho-escuras, pelo protórax mais cilíndrico, pelo pronoto sem gibosidades e pela pontuação dos élitros mais rasa. Em R. pulverulenta (Figs 1 e 10) a cabeça, o protórax e o escutelo são alaranjados, concolores com os élitros, assim como as epipleuras; o protórax é mais expandido no meio dos lados, o pronoto apresenta quatro gibosidades e a pontuação elitral é mais profunda. O pouco material examinado das duas espécies não permitiu constatar outras diferenças ou indicar as constatadas como possíveis variações intra-específicas. 


\section{Rhopalophora prolixa Monné, 1989}

Figs 7,13

Rhopalophora (Rhopalophora) prolixa Monné, 1989: 737, fig. 1. Rhopalophora prolixa; Monné, 2005: 534 (catálogo); Monné \& Hovore, 2006: 129 (checklist).

Macho. Colorido geral preto; protórax alaranjado. Cabeça opaca, revestida por pubescência amarelo-dourada mais densa no dorso e na fronte; com pontos profundos e esparsos na fronte e vértice. Genas com pontos finos, corrugados e pubescência esparsa. Margem inferior dos lobos oculares inferiores ornada com franja de pilosidade esbranquiçada e sedosa. Clípeo fina e densamente pontuado com pubescência amarelada. Submento glabro, brilhante e irregularmente pontuado-rugoso. Antenas ultrapassam o ápice elitral em 5,0 artículos. Escapo um pouco robusto, sem sulco dorsal, apenas deprimido na base, mais curto que metade do comprimento do III; muito fina e densamente pontuado-corrugado em toda a superfície, com pubescência esbranquiçada esparsa e algumas cerdas esbranquiçadas e semieretas. Antenômero III com sulco raso; IV com dois terços do comprimento do III e do V; V-X com comprimentos crescentes, mais longos que o III, especialmente os VI-VIII; XI cerca de um quinto mais longo que o III. Protórax (Fig. 13) subcilíndrico, pouco atenuado do meio para a margem anterior; apenas expandido no meio dos lados e no terço basal. Pronoto opaco, com as projeções látero-basais e látero-medianas pouco aparentes; revestido por densa pilosidade dourada, compacta que oblitera totalmente o tegumento, exceto área centro-mediana glabra; base com pubescência esbranquiçada. Lados do protórax com pilosidade igual à do pronoto e com pubescência esbranquiçada na base. Em áreas em que a pilosidade não oblitera o tegumento, observam-se pontos finos, profundos, esparsos no pronoto e mais aparentes nos lados do protórax. Prosterno brilhante, com rugas transversais finas, rasas e irregulares; a cada lado, na metade anterior, área mais ou menos arredondada, opaca e muito finamente estriada; região centro-basal e processo prosternal revestidos por pilosidade serícea; essa pilosidade acompanha a margem anterior das cavidades coxais e se continua, na base, nos lados do protórax e no pronoto. Mesosterno, metasterno e urosternitos revestidos por pubescência sedosa com brilho oliváceo. Escutelo revestido por pilosidade serícea densa. Élitros pouco deprimidos no dorso e apenas no quarto basal. Superfície revestida por pilosidade serícea ou sedosa com brilho oliváceo que oblitera o tegumento exceto lados da metade basal. Epipleuras, na metade basal, verticais, subglabras e com pontos muito grossos, profundos e contíguos; os pontos progressivamente menores para o ápice e quase totalmente obliterados pela pubescência; margem sem pontos ásperos. Extremidades elitrais obliquamente truncadas com espinho curto e delgado no ângulo sutural; ângulo externo dentiforme. Fêmures com pubescência esbranquiçada esparsa; pedúnculo com alguns pontos ásperos providos de cerdas curtas e esbranquiçadas. Metafêmures ultrapassam o ápice elitral por todo o comprimento da clava.
Fêmea. Antenas ultrapassam o ápice elitral em 3,0 artículos; escapo com metade do comprimento do III e mais curto que o IV; antenômeros III-XI com pubescência esbranquiçada aparente; III com sulco pouco aparente a ausente; V-VII subiguais e pouco mais longos que o III; XI apenas mais curto que o III. Protórax subparalelo nos lados, a largura da margem anterior subigual à da posterior. Prosterno sem áreas diferenciadas, com rugas finas e regulares em toda a superfície. Pedúnculo dos fêmures com pubescência aparente, as clavas mais delgadas; metafêmures ultrapassam o ápice elitral por dois terços do comprimento da clava.

Dimensões, macho/fêmea, respectivamente. Comprimento total, 11,0/10,0; comprimento do protórax, 2,3/2,0; maior largura do protórax, 1,8/1,7; largura da margem anterior do protórax, 1,5/1,5; comprimento do élitro, 7,8/7,2; largura umeral, 2,3/2,2.

Material-tipo. Holótipo macho, BrasiL, Minas Gerais: Pedra Azul (700 m), XI.1972, C.A.C. Seabra \& F.M. Oliveira leg. (MNRJ). Parátipos: 5 machos, 3 fêmeas com os mesmos dados do holótipo; Bahia: Encruzilhada (Motel da Divisa, Estrada RioBahia, km 965, 960 m): macho, XI.1971, macho, 2 fêmeas, XI.1972, fêmea, XII.1975, C.A.C. Seabra e O. Roppa leg. (MNRJ). Examinados parátipo macho e dois parátipos fêmea.

Comentários. Pelo colorido geral preto com protórax alaranjado, $R$. prolixa assemelha-se a $R$. collaris, $R$. occipitalis e $R$. paraensis (Figs 6, 8 e 9) e distingue-se pela densa pilosidade amarelo-dourada que reveste o pronoto e lados do protórax e que oblitera o tegumento; pelo escapo sem sulco dorsal; pelo antenômero IV com dois terços do comprimento do III e do V, o III com sulco raso e pelo protórax praticamente não atenuado para frente. Naquelas três espécies, a pubescência do pronoto e lados do protórax é esparsa, o escapo tem sulco dorsal, o antenômero IV tem metade do comprimento do III e do V, o III não sulcado, e o protórax é atenuado para a margem anterior.

Material-examinado. BRASIL. Bahia: Encruzilhada (Motel da Divisa, Estrada Rio-Bahia, km 965, 960 m), macho XI.1974, fêmea, XII.1975, Seabra \& Roppa leg. (MNRJ, parátipos). Minas Gerais: Pedra Azul (700 m), fêmea, XI.1972, Seabra \& Oliveira leg. (MNRJ, parátipo).

\section{Rhopalophora collaris (Germar, 1824)}

\section{Figs 6, 16}

Callichroma collare Germar, 1824: 498.

Rhopalophora collaris; Germar in Guérin-Méneville, 1839: 330

(sin.); Monné, 2005: 532 (catálogo); Monné \& Hovore, 2006: 129 (checklist).

Rhopalophora (Rhopalophora) collaris; Chevrolat, 1859: 59. Ropalophora collaris; Bondar, 1929: 92 (hosts) (error). Rhopalophora sanguinicollis Audinet-Serville, 1834: 101. Rhopalophora bicolor Guérin-Méneville, 1844: 330.

Macho. Cabeça, antenas e pernas pretas. Protórax alaranjado. Escutelo preto a alaranjado. Élitros pretos, mais acastanhados no disco. Mesosterno, metasterno e urosternitos pretos. Fronte e dorso da cabeça opacos, densamente microesculturados, com 

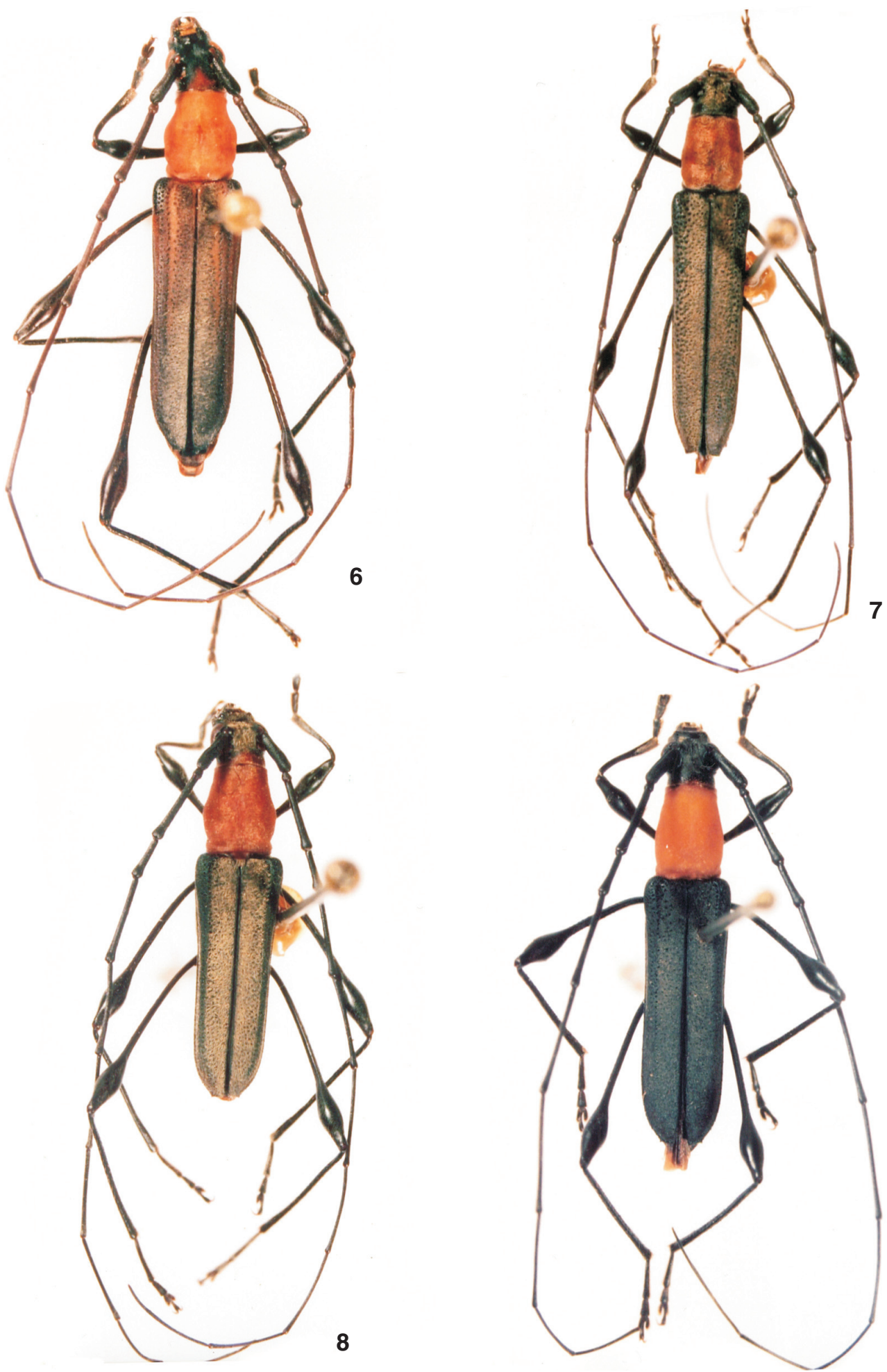

Figuras 6-9. Habitus: (6) Rhopalophora collaris, macho, 12,9 mm; (7) R. prolixa, parátipo macho, 11,0 mm; (8) R. occipitalis, macho, 10,5 $\mathrm{mm}$; (9) R. paraensis, parátipo macho, $11,3 \mathrm{~mm}$. 

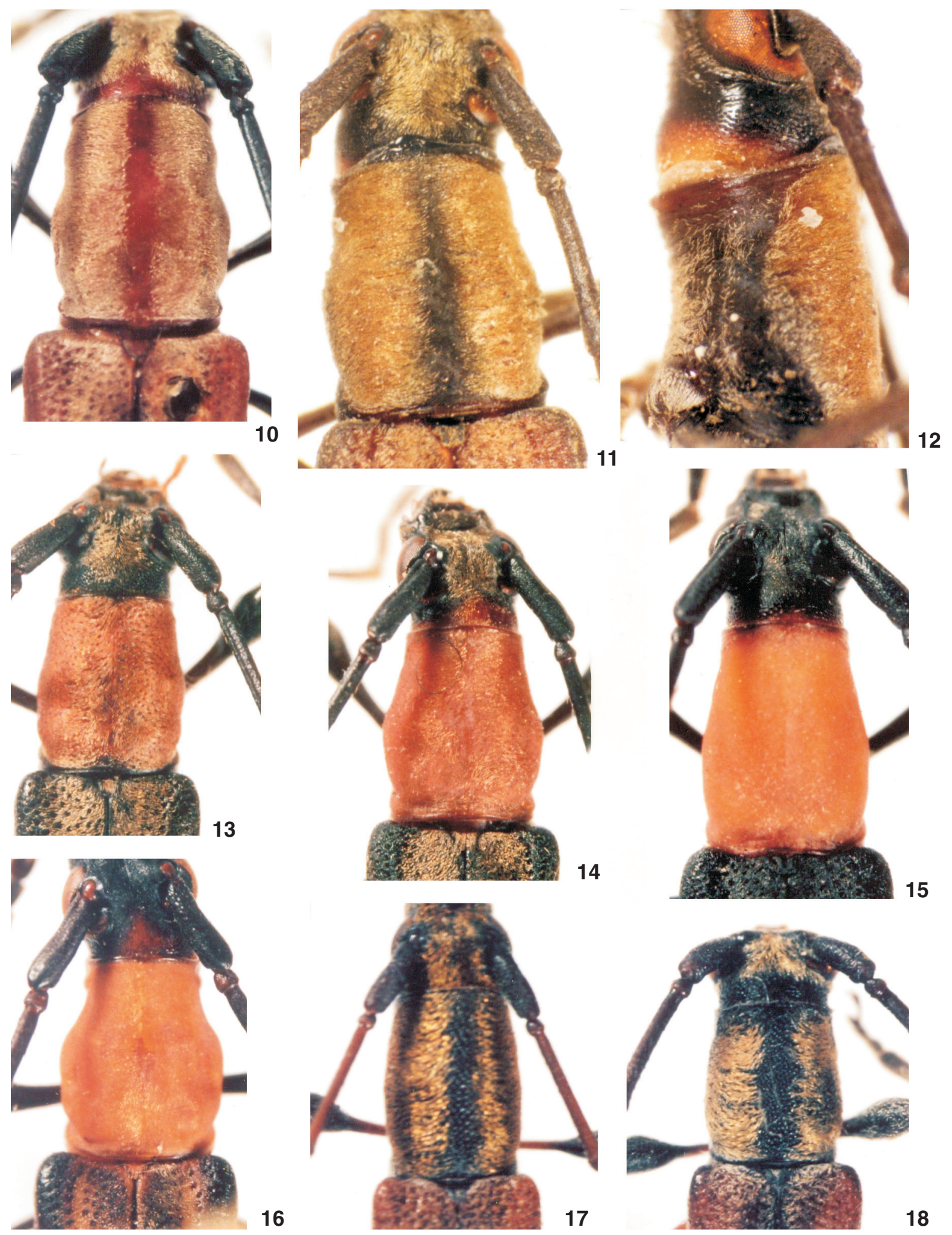

Figuras 10-18. Protórax: (10) R. pulverulenta; (11-12) R. venezuelensis; (13) R. prolixa; (14) R. occipitalis; (15) R. paraensis; (16) R. collaris; (17) R. casignata; (18) R. dyseidia. 
pubescência curta, amarelo-dourada, mais aparente na fronte. Clípeo com pontos finos e rasos e pubescência amarelada mais esparsa do que na fronte. Genas praticamente glabras, com pontos esparsos. Margem inferior dos lobos oculares inferiores sem faixa de pilosidade, mas com pontos aparentes. Face ventral da cabeça subglabra, brilhante, com rugas grossas e irregulares; mais finas e com pontos irregulares no submento. Antenas ultrapassam o ápice elitral em 4,5-5,0 artículos. Escapo cilíndrico, delgado, com sulco dorsal da base até quase o ápice, com dois terços do comprimento do III; subglabro, fina e muito densamente pontuado em toda a superfície. Antenômeros III-V muito fina, rasa e densamente pontuados e com pubescência esparsa; VI-XI com pubescência esbranquiçada mais aparente; V-VIII com comprimentos crescentes, mais longos que o III; XI cerca de um quinto mais longo que o III. Protórax (Fig. 16) evidentemente estreitado no terço anterior, depois abruptamente expandido e bituberculado nos lados; tubérculo mediano arredondado, maior e mais projetado e outro no terço posterior, menor e menos manifesto. Pronoto opaco, impontuado; pubescência amarelo-dourada muito curta e pouco aparente; com duas gibosidades látero-basais evidentes e duas látero-medianas menos pronunciadas. Lados do protórax opacos, glabros, com pontos muito esparsos. Prosterno brilhante, glabro, com rugas transversais; a cada lado, logo após a constrição anterior, com pequena área circular com rugas mais finas e pontos entremeados; processo prosternal revestido por densa pilosidade branco-amarelada. Mesosterno, metasterno e urosternitos revestidos por pubescência serícea ou com brilho oliváceo. Escutelo revestido por densa pilosidade amarelo-dourada. Élitros deprimidos no disco, especialmente na região basal. Com pontos grossos e profundos na metade basal, irregularmente alinhados nos lados do disco; no disco mais irregulares e progressivamente menores e rasos até quase inaparentes no terço apical. Dorso dos élitros revestido por pubescência amarelo-dourada, densa, oblitera parcialmente os pontos nos dois terços basais e totalmente no terço apical; lados elevados dos élitros, glabros. Epipleuras verticais, glabras; com pontos grossos, profundos e mais ou menos alinhados na metade basal, depois gradualmente menores e mais rasos para os ápices. Extremidades elitrais estreitamente truncadas, com espinho curto e delgado nos ângulos sutural e externo. Fêmures com pubescência e pontos ásperos esparsos no pedúnculo. Metafêmures ultrapassam o ápice elitral por todo o comprimento da clava.

Fêmea. Antenas ultrapassam o ápice elitral em 3,0-4,0 artículos; antenômeros V-VIII e XI iguais em comprimento e mais longos que o dobro do comprimento do IV; XI pouco mais longo que o III. Prosterno sem áreas diferenciadas de rugas e pontos. Metafêmures ultrapassam o ápice elitral pela metade ou dois terços do comprimento da clava.

Dimensões, macho/fêmea, respectivamente. Comprimento total, 9,2-13,4/10,0-12,7; comprimento do protórax, 2,0-3,0/ 2,2-2,8; maior largura do protórax, 1,7-2,7/1,8-2,3; largura da margem anterior do protórax, 1,2-1,8/1,2-1,5; comprimento do élitro, 5,5-9,0/7,2-9,0; largura umeral, 1,2-1,8/1,3-1,5.
Variabilidade. Os dois exemplares procedentes da Bolívia apresentam a região posterior da cabeça vermelha, à semelhança de R. occipitalis. Alguns exemplares apresentam, na região deprimida do dorso dos élitros, faixa estreita, irregular e mais amarelada a cada lado do úmero até quase o meio do élitro. A pilosidade do mesosterno, metasterno e urosternitos pode ser esbranquiçada e muito curta ou ter aspecto sedoso, com brilho oliváceo.

Material-tipo. Os tipos de Callichroma collare Germar, 1824 e de Rhopalophora bicolor Guérin-Méneville, 1844, descritas do Brasil sem maiores detalhes de procedência, não foram examinados. Segundo Monné (2005) desconhece-se em qual instituição estão depositados.

Rhopalophora sanguinicollis Audinet-Serville, 1834, aparentemente, foi descrita com base em um macho procedente do Brasil. Entretanto, Audinet-Serville (1834: 101) menciona: "Collections de MM le comte Dejean et Dupont ainsi que la mienne.", o que leva a supor que teve em mãos mais de um exemplar. Assim, a indicação de holótipo feita por TAVAKILIAN (1999) está, provavelmente, equivocada. Examinado diapositivo de um síntipo macho, descrito do Brasil e depositado no BMNH (ex-coleção Audinet-Serville).

Comentários. Pelo colorido preto com o protórax alaranjado e pronoto opaco e subglabro, assemelha-se a $R$. occipitalis e $R$. paraensis (Figs 8 e 9). Distingue-se de ambas pelos caracteres fornecidos na chave.

Material examinado. BRASIL. Rio de Janeiro: Rio de Janeiro (Corcovado), fêmea, 20.X.1955, D. Zajciw leg. (MNRJ). Paraná: Arapongas, fêmea, I.1952, macho, III.1952, F. Justus leg. (DZUP); Jaguariaíva, fêmea, XII.1969, macho, 2 fêmeas, XII.1970, F. Giacomel leg. (DZUP); Olho d'Água, 2 machos, V.1943, F. Justus leg. (DZUP); Rondon, fêmea, IX.1952, F. Plaumann leg. (DZUP); Santa Mariana, macho, 10.XI.1949, H. Zellibor co leg. (MNRJ). Santa Catarina: Seara (Nova Teutônia), 3 fêmeas, X.1956, 3 machos, fêmea, X.1972, F. Plaumann leg. (DZUP), macho, 8.XI.1952, F. Plaumann leg. (MNRJ). Rio Grande do Sul: Santo Augusto, macho, 2 fêmeas, X.1966, O. Roppa leg. (MNRJ). BOLÍviA. Santa Cruz: Buena Vista (17²7'68”S 69 39'63" W, 380 m), 2 fêmeas, 20.II.1999 (Malaise), L. Stange leg. (ACMB). ARGenTina. Tucumán: macho (MNRJ).

\section{Rhopalophora occipitalis Chevrolat, 1859}

$$
\text { Figs 8, } 14
$$

Rhopalophora (Rhopalophora) occipitalis Chevrolat, 1859: 59. Rhopalophora occipitalis ; Monné, 2005: 534 (catálogo); Monné \& Hovore, 2006: 129 (checklist).

Macho. Colorido geral, preto. Protórax e região posterior da cabeça, após os lobos oculares, vermelhos. Gula preta a vermelha. Fronte e vértice opacos, revestidos por pilosidade sedosa amarelada e com alguns pontos grossos e esparsos. Clípeo com pontos finos e pilosidade mais esparsa que a da fronte. Genas com pontos finos, rasos e pubescência esbranquiçada pouco aparente. Margem inferior dos lobos oculares inferiores ornada com faixa de pilosidade esbranquiçada. Submento subglabro, 
pontuado-rugoso. Gula com rugas grossas e espaçadas. Antenas ultrapassam o ápice elitral em 5,0 artículos. Escapo cilíndrico, delgado com sulco manifesto da base ao ápice, com cerca de dois terços do comprimento do III; subopaco, quase glabro com pontos finos e densos a corrugados em toda a superfície. Antenômeros III-XI opacos, subglabros, com pubescência esbranquiçada gradualmente mais aparente a partir do VI. Antenômero III sem sulco. Antenômero IV mais curto que metade do comprimento do V; V-IX mais longos que o III; XI cerca de dois terços mais longo que o III. Protórax (Fig. 14) subcilíndrico, gradualmente atenuado do meio para a margem anterior; apenas expandido no meio e no terço posterior, a maior largura no meio. Pronoto opaco, sem pontos, com pubescência amarelo-dourada curta e pouco aparente; gibosidades láteromedianas praticamente ausentes, as látero-posteriores mais aparentes. Lados do protórax opacos, glabros e impontuados ou com pontos rasos, muito esparsos e pubescência esbranquiçada quase inaparente. Prosterno com estrias transversais finas em toda a superfície; na metade anterior, a cada lado, com área pouco conspícua com estrias mais sinuosas e pontos esparsos; com pubescência esbranquiçada densa à frente e no processo prosternal, no restante subglabro, brilhante; em alguns exemplares, estreita faixa de pubescência esbranquiçada a cada lado no limite com os lados do protórax. Mesosterno, metasterno e urosternitos com pubescência serícea ou sedosa com brilho oliváceo. Escutelo revestido por pubescência sedosa branco-amarelada. Élitros deprimidos no dorso, especialmente no terço anterior; com pontos grossos, profundos e densos, não alinhados e progressivamente mais finos e rasos em direção aos ápices. Dorso revestido por pilosidade serícea ou branco-amarelada, sedosa que oblitera o tegumento. Úmeros e lados dos élitros, incluindo parte das epipleuras, glabros, formando faixa escura lateral em cada élitro; com pontuação semelhante à do dorso dos élitros. Epipleuras verticais até além do meio; na metade inferior, com pilosidade sedosa branco-amarelada semelhante à do dorso dos élitros; margem sem pontos ásperos, com algumas cerdas rijas e curtas. Extremidades dos élitros transversalmente truncadas ou ligeiramente sinuosas, com espinho curto nos ângulos externo e sutural. Fêmures com pubescência pouco aparente e pontos ásperos com cerdas curtas, muito esparsos. Metafêmures ultrapassam o ápice elitral pelo comprimento das clavas.

Fêmea. Antenas ultrapassam o ápice elitral em 3,0 artículos; antenômero XI tão longo quanto o III. Prosterno inteiramente estriado, sem áreas diferenciadas. Metafêmures ultrapassam o ápice elitral pela metade do comprimento das clavas que são mais delgadas do que as do macho.

Dimensões, macho/fêmea, respectivamente. Comprimento total, 9,3-10,7/8,7-9,4; comprimento do protórax, 2,3-2,7/ 2,0-2,5; maior largura do protórax, 1,7-2,2/1,4-1,7; largura na margem anterior do protórax, 1,3-1,5/1,2-1,3; comprimento do élitro, 6,3-7,2/6,2-6,4; largura umeral, 2,2-2,5/2,0-2,2.

Material-tipo. Pela descrição original, Chevrolat (1859) baseou a descrição da espécie em mais de um exemplar com procedência do Brasil (Bahia). Examinado um síntipo macho depositado no BMNH que porta as etiquetas: 1) Type; 2) Rhopalophora occipitalis Chevr., Brasil; 3) Rh.occipitalis Chv., Arc. 1859, N.G. Brasil; 4) Rhopalophora occipitalis Chv. Arcana, collaris mihi, h. in Brasília, Bahya, D. Solier (etiqueta de Dejean); 5) Bowr. Chevr. 63.47*.

Comentários. Vide R. paraensis.

Material examinado. Brasil. Ceará: Icó, 2 machos, III.1939, D. C. Alves leg. (MZSP). Rio Grande do Norte: Taipú, fêmea, Pe. Pereira leg. (MZSP). Paraíba: Soledade (Juazeirino), macho, III.1956, A.G. Silva leg. (MNRJ). Sergipe: Canindé do São Francisco (Fazenda Esplanada; Projeto Xingó, Biodiversidade; Malaise), fêmea, 17.VIII.2000 (área 5), macho, 7.IX.2000 (área 2), L. Ianuzzi leg. (UFPB). Bahia: Cândido Sales, macho, XI.1972, Seabra \& Roppa leg. (MNRJ); Palmeiras, macho, II.1992, O. Roppa leg. (MNRJ).

\section{Rhopalophora paraensis Martins \& Napp, 1989}

\section{Figs 9, 15}

Rhopalophora (Rhopalophora) paraensis Martins \& Napp, 1989: 58 , fig. 1.

Rhopalophora paraensis; Monné, 2005: 534 (catálogo); Monné \& Hovore, 2006: 129 (checklist).

Macho. Colorido geral, preto. Protórax vermelho-alaranjado. Cabeça fortemente opaca, com pubescência esbranquiçada muito curta, mais aparente na fronte e no clípeo. Genas com pontos maiores e glabras. Margem inferior dos lobos oculares inferiores contornada por pontos grossos, sem pilosidade. Face ventral da cabeça com rugas grossas e espaçadas; submento pontuado-rugoso com pilosidade esbranquiçada pouco aparente. Antenas ultrapassam o ápice elitral em 4,0-5,0 artículos. Escapo cilíndrico, delgado, com sulco longitudinal da base até quase o ápice, com dois terços do comprimento do III e pouco mais longo que o IV; subglabro, subopaco, fina e densamente pontuado a corrugado em toda a superfície. Antenômeros III-V muito fina, rasa e densamente pontuados, pubescência quase inaparente e raras cerdas curtas, castanhas, na face inferior; VIXI com pubescência esbranquiçada pouco aparente. Antenômero IV mais curto que metade do comprimento do $\mathrm{V}$; V-X mais longos que o III, especialmente os VI-IX; XI cerca de vez e meia mais longo que o III. Protórax (Fig. 15) cilíndrico, pouco e gradualmente atenuado do terço posterior para a margem anterior, sem tubérculos laterais; maior largura após o meio. Pronoto fortemente opaco, glabro, sem pontos; subplano, as gibosidades látero-basais pouco aparentes, as látero-medianas ausentes. Lados do protórax opacos, glabros e impontuados. Prosterno, na metade anterior, glabro, com rugas transversais regulares; na posterior, opaco com pubescência serícea curta, mais aparente no centro e no processo prosternal; a cada lado, na metade anterior, com pequena área de tegumento mais escuro e brilhante, com rugas mais finas e sem pontos. Mesosterno, metasterno e urosternitos revestidos por pubescência serícea 
muito curta e densa. Escutelo revestido por pubescência serícea densa. Élitros deprimidos no disco, especialmente no terço basal. Superfície revestida por pilosidade branco-sedosa, curta, oblitera parcialmente os pontos especialmente no terço apical. Úmeros e lados elevados dos élitros, glabros no terço basal. Epipleuras verticais até pouco além do meio; glabras no terço basal, depois pubescentes; margem, no terço apical, com pontos ásperos cada um provido com cerda curta e rija. Extremidades elitrais estreitamente truncadas com curto espinho no ângulo externo, o ângulo sutural quase inerme. Fêmures subglabros; pedúnculos sulcados e carenados, com pontos ásperos muito esparsos, providos de cerdas curtas; clavas com pubescência esbranquiçada pouco aparente. Metafêmures ultrapassam o ápice elitral por todo o comprimento da clava.

Fêmea. Desconhecida.

Dimensões, macho. Comprimento total, 10,0-11,3; comprimento do protórax, 2,3-2,8; maior largura do protórax, 1,72,0; largura da margem anterior do protórax, 1,3-1,6; comprimento do élitro, 6,8-7,7; largura umeral, 2,2-2,6.

Material-tipo. Holótipo macho, Brasil, Pará: Serra Norte (Três Alfa), 12.V.1984, T. Pimentel leg. (MPEG). Parátipos: Pará: 2 machos, mesmos dados do holótipo (MPEG, MZSP), macho (Est. Manyonês), 6.V.1984 (MPEG), macho (Est. do Fofoca), 14.V.1984, M.F. Torres leg. (DZUP), macho, 29.II.1984 ("Flight trap") (MPEG), macho (Rio Salado), 16.V.1984 ("Flight trap") (MZSP), macho (Rio Salobo), 19-22.V.1984 ("Flight trap") (DZUP), macho, 11.VIII.1984 (DZUP).

Comentários. Semelhante a $R$. occipitalis. Além dos caracteres fornecidos na chave, $R$. paraensis não tem pilosidade na margem inferior dos lobos oculares inferiores, o pedúnculo dos fêmures é praticamente glabro, a margem das epipleuras apresenta pontos ásperos e o mesosterno, metasterno e urosternitos são revestidos por pubescência curta. Em R. occipitalis a margem inferior dos lobos oculares é ornada com pilosidade esbranquiçada, o pedúnculo dos fêmures é pubescente, a margem das epipleuras é desprovida de pontos ásperos e o mesosterno, metasterno e urosternitos são revestidos por pubescência alongada e sedosa, com brilho amarelado.

Material examinado. Brasil, Pará: Serra Norte, parátipo macho (Três Alfa), 12.V.1984, T. Pimentel leg. (MPEG, MZSP), parátipo macho (Rio Salado), 16.V.1984 ("Flight trap") (MZSP), parátipo macho (Rio Salobo), 19-22.V.1984, parátipo macho, 11.VIII.1984 (DZUP), parátipo macho (Est. do Fofoca), 14.V. 1984, M.F. Torres leg. (DZUP).

\section{AGRADECIMENTOS}

À S. Schute (BMNH) pelo envio do síntipo de Rhopalophora venezuelensis; a M. A. Monné (MNRJ) e U.R. Martins (MZSP) pelo empréstimo de material-tipo de diversas espécies e a A.M. Sakakibara (DZUP) pela execução das fotos. Esta é a contribuição 1785 do Departamento de Zoologia, Universidade Federal do Paraná.

\section{LITERATURA CITADA}

Audinet-Serville, J.G. 1834. Nouvelle classification de la famille des longicornes (suite). Annales de la Société Entomologique de France (1) 3: 5-110.

Bondar, G. 1929. Cultura da laranjeira no Brasil. São Paulo, Chácaras e Quintais, 138p.

Chevrolat, L.A. 1859. Essai monographique sur le genre Rhopalophora. Arcana Naturae 1: 57-64.

Germar, E.F. 1824. Insectorum species novae aut minus cognitae, descriptionibus illustratae. Halae, Hendel \& Sons, XXIV+624p.

Germar, E.F. 1839. In: F.E. Guérin-Ménéville. Note synonymique sur les cérambycins décrits par M. Germar, dans son Insectorum species novae aut minus cognitae, descriptionibus illustratae, Halae, 1824. Magasin de Zoologie 1839: 329-331.

Giesbert, E.F. \& J.A. Chemsak. 1993. A review of the Rhopalophorini (Coleoptera: Cerambycidae) of North and Central America. Insecta Mundi 7(1-2): 27-64.

GuÉRIN-MÉneville, F.E. 1844. Iconographie du règne animal de G. Cuvier, ou réprésentation d'après nature de l'une des espèces les plus remarquables et souvent non figurées de chaque genre d'animaux. Avec un texte descriptif mis au courant de la science.Ouvrage pouvant servir d'atlas a tous les traités de zoologie. Paris, Baillière, Insectes, 7, IV: 576p.

LeConte, J.L. 1850. An attempt to classify the longicorn Coleoptera of the part of America, north of Mexico. Journal of the Academy of Natural Sciences of Philadelphia (2) 2: 5-38.

LeConte, J.L. 1873. Classification of the Coleoptera of North America. Part II. Smithsonian Miscellaneous Collections 11 (265): 279-348.

Mendes, D. 1940. Rhopalophora neivai, nova espécie da família Cerambycidae (Coleoptera). Revista de Entomologia 11: 380-382.

Marques, M.I. \& D.S. NAPp. 2003. Análise cladística da tribo Rhopalophorini Blanchard, 1845 (Coleoptera, Cerambycidae). Revista Brasileira de Entomologia 47 (4): 491-545.

Martins, U.R. \& D.S. NAPP. 1989. Rhopalophorini (Coleoptera, Cerambycidae, Cerambycinae): descrições, sinonímias e novas combinações. Revista Brasileira de Entomologia 33(1): 57-65.

Mermudes, J.R.M. \& D.S.NAPP. 2004. Comparative morphological study of the Neotropical Cleomenini and their transference to the tribes Rhopalophorini Blanchard and Rhinotragini Thomson (Coleoptera, Cerambycidae, Cerambycinae). Revista Brasileira de Entomologia 48 (2): 251-272.

Monné, M.A. 1989. Novos táxons e sinonímia em Rhopalophorini (Coleoptera, Cerambycidae, Cerambycinae). Revista Brasileira de Biologia 49 (3): 737-741.

Monné, M.A. 2001. Catalogue of the Neotropical Cerambycidae (Coleoptera) with known host plant - Part II: Subfamily Cerambycinae, Tribes Graciliini to Trachyderini. Publicações Avulsas do Museu Nacional 90: 1-119. 
Monné, M.A. 2005. Catalogue of the Cerambycidae (Coleoptera) of the Neotropical Region. Part I. Subfamily Cerambycinae. Zootaxa 946: 1-765.

Monné, M.A. \& F.T. Hovore. 2006. Checklist of the Cerambycidae or longhorned beetles, of the Western Hemisphere. Rancho Dominguez, BioQuip Publications, 394p.
NAPP, D.S. \& J.R. MERMUdes. 2001. Revision of the genus Listroptera Audinet-Serville and description of Aguassay, new genus (Coleoptera, Cerambycidae, Cleomenini). The Coleopterists Bulletin 55 (1): 1-9.

TAVAKILIAN, G. 1999. Longicornes. Available online at: http:// www.orleans.ird.fr/titan [Accessed: 01.X.2008].

Submitted: 10.XI.2008; Accepted: 09.VI.2009.

Editorial responsability: Gabriel Mejdalani 